\title{
Preparation and in vitro/in vivo characterization of enteric-coated nanoparticles loaded with the antihypertensive peptide VLPVPR
}

This article was published in the following Dove Press journal:

International Journal of Nanomedicine

3 April 2014

Number of times this article has been viewed

\section{Haiyan Sun \\ Dong Liu \\ Yan Li \\ Xuwei Tang \\ Yanli Cong}

Shenzhen Key Laboratory of Fermentation, Purification and Analysis, Shenzhen Polytechnic, Guangdong, People's Republic of China
Correspondence: Dong Liu Department of Applied Biotechnology, Shenzhen Polytechnic, Shenzhen, Guangdong 5I8055, People's

Republic of China

Tel +86755260I 9170

Fax +8675526019169

Email liudongsz@szpt.edu.cn

\begin{abstract}
Our previous study revealed that the peptide Val-Leu-Pro-Val-Pro-Arg (VLPVPR), which was prepared using deoxyribonucleic acid recombinant technology, effectively decreased the blood pressure of spontaneous hypertensive rats; however, the effect only lasts 6 hours, likely due to its low absorption in the gastrointestinal tract. To overcome this problem, the purpose of this study was to characterize (methoxy-polyethylene glycol)-b-poly(D,L-lactide-co-glycolide)-bpoly(L-lysine) nanoparticles as in vitro and in vivo carriers for the effective delivery of VLPVPR. In our study, the VLPVPR nanoparticles were prepared using a double emulsion method, coated with Eudragit S100, and freeze-dried to produce enteric-coated nanoparticles. The optimized parameters from the double emulsion method was obtained from orthogonal experiments, including drug loading (DL) and encapsulated ratio (ER) at $6.12 \%$ and $86.94 \%$, respectively, and the average particle size was below $100 \mathrm{~nm}$. The release experiment demonstrated that the nanoparticles were sensitive to $\mathrm{pH}$ : almost completely released at $\mathrm{pH} 7.4$ after 8 hours, but demonstrated much less release at $\mathrm{pH} 4.5$ or $\mathrm{pH} 1.0$ in the same amount of time. Therefore, the nanoparticles are suitable for enteric release. In vivo compared with the untreated group, the medium and high doses of orally administered VLPVPR nanoparticles reduced blood pressure for more than 30 hours, demonstrating that these nanoparticles have long-lasting and significant antihypertensive effects in spontaneously hypertensive rats.
\end{abstract}

Keywords: mPEG-PLGA-PLL, in vivo studies, Val-Leu-Pro-Val-Pro-Arg peptide, entericcoated, nanoparticle, antihypertensive peptide

\section{Introduction}

Hypertension is defined as a sustained elevation of systolic blood pressure above $140 \mathrm{mmHg}$ and/or diastolic blood pressure above $90 \mathrm{mmHg}$. Overall, the prevalence of hypertension appears to be around $30 \%-45 \%$ of the general population, with a steep increase with aging. ${ }^{1}$ The cause of hypertension is variable, such as increased peripheral vascular smooth muscle tone, which leads to increased arteriolar resistance and reduced capacitance of the venous system. ${ }^{2}$ Angiotensin-converting enzyme (Enzyme Commision (EC) 3.4.15.1) plays an important role in blood pressure maintenance by regulating the renin-angiotensin system. It does that by converting angiotensin I to angiotensin II, which constricts the vessels. During the past two decades, numerous physiologically active peptides have been discovered in the hydrolysates of various food proteins. Among them, antihypertensive peptides (AHPs) have received considerable attention because they are potent angiotensin-converting enzyme inhibitors with acceptable antihypertensive effects and could serve as alternative therapeutics for patients with certain hypertension. ${ }^{3-5}$ To exert their antihypertensive effects in 
vivo, these peptides must remain intact when absorbed across the intestinal epithelium. Our previous study revealed that the AHP Val-Leu-Pro-Val-Pro-Arg (VLPVPR), which was prepared on a large scale using deoxyribonucleic acid recombinant technology, effectively decreased the blood pressure of spontaneously hypertensive rats, but the effect only lasts 6 hours, likely because this AHP was poorly absorbed in the gastrointestinal tract. ${ }^{6,7}$

To overcome this problem, we prepared enteric-coated nanoparticles loaded with the antihypertensive peptide VLPVPR. Nanoparticles have better properties for transporting protein drugs and improved pharmacokinetic profiles in vivo because their nanoscale size helps them penetrate tissues efficiently through capillaries and epithelial linings. ${ }^{8,9}$ In addition, because of VLPVPR's high hydrophilicity, we utilized (methoxy-polyethylene glycol)-b-poly(D,L-lactideco-glycolide)-b-poly(L-lysine) (mPEG-PLGA-PLL) as the entrapping material. The polymer mPEG-PLGA-PLL is widely used in the preparation of microparticles because it is nontoxic, well tolerated by the human body, biodegradable, and biocompatible..$^{10,11}$ The double emulsification method was utilized to encapsulate proteins in this study. AHP is better absorbed in the ileum and the large intestine than in the jejunum. Thus, a polymer that would release the drug at $\mathrm{pH}>7$ would be suitable for oral AHP delivery; the polymer Eudragit S100 has this characteristic. ${ }^{12}$ When utilized to entrap VLPVPR in nanoparticles, it would be expected to protect the peptide from degradation by gastric juices and allow it to be released in regions of the gastrointestinal tract with $\mathrm{pH}>7$, such as the large intestine or the colon where proteolytic enzymes are scant. The enteric-coated nanoparticles were characterized by shape (scanning electron microscopy), size (laser diffraction method), and drug loading. Their in vitro release behavior was investigated in phosphate buffer at various $\mathrm{pH}$ values, and the in vivo bioactivity of the nanoparticles was studied in rats.

\section{Materials and methods Materials}

The recombinant antihypertensive peptide VLPVPR was prepared using genetic engineering technology in our laboratory (Shenzhen Key Laboratory, Shenzhen, People's Republic of China). Eudragit S100 was purchased from Shanghai Chineway Pharmaceutical Tech Co, Ltd (Shanghai, People's Republic of China). Poly(vinyl alcohol) (PVA) was obtained from SigmaAldrich (St Louis, MO, USA) with a molecular weight (MW) of $130-230 \mathrm{kD}$, and $87 \%-89 \%$ hydroxylated. mPEG-PLGAPLL, with a polyethylene glycol MW of 2,000 and a glycolic acid:lactic acid (GA:LA) of 8:2, was prepared by Yourong
Duan's Lab at the Shanghai Cancer Institute, Shanghai, People's Republic of China. Pure chromatographic acetonitrile was utilized. Other reagents were of analytical grade.

\section{Experimental animals}

Twelve-week-old male spontaneously hypertensive rats (SHR) with a body weight of 250-300 g were purchased from Shanghai SLAC Laboratory Animal Co, Ltd, Shanghai, People's Republic of China. Each group included six rats. The rats were fed standard low-fat chow and had free access to water in a $25^{\circ} \mathrm{C} \pm 1^{\circ} \mathrm{C}$ environment with $55 \% \pm 5 \%$ relative humidity and regular light. Rats entered the study when their systolic blood pressure (SBP) rose above $180 \mathrm{mmHg}$. The experiments were performed after 1 week of training for the rats in the animal facility. All procedures were in accordance with the Regulations of Experimental Animal Administration issued by the Ministry of Science and Technology of the People's Republic of China (http://www.most.gov.cn). The animal study protocols were approved by the Institutional Animal Care and Use Committee at Shenzhen Polytechnic, Shenzhen, People's Republic of China.

\section{Methods}

\section{Characterization of VLPVPR}

The concentration of VLPVPR was determined by highperformance liquid chromatography (HPLC) (Agilent 1200 Variable Wavelength Detector; Santa Clara, CA, USA) with a C18 chromatographic column (Phenomenex Synergi; Torrance, CA, USA, $4.6 \times 250 \mathrm{~mm}, 5 \mu \mathrm{m})$. The mobile phase was acetonitrile:water:trifluoroacetic acid 18:82:0.1.

\section{Preparation of nanoparticles}

Double-emulsify method

mPEG-PLGA-PLL was utilized to form nanoparticles using the double-emulsify method. ${ }^{13,14}$ VLPVPR (5 mg) was dissolved in $0.2 \mathrm{~mL}$ water to form the inner water phase. $\mathrm{mPEG}$ PLGA-PLL (50 mg) was dissolved in $1 \mathrm{~mL}$ dichloromethane to form the oil phase. A 1\% PVA solution was utilized as the outer water phase. The inner phase was added to the oil phase and emulsified with ultrasound $(200 \mathrm{~W}, 5$ seconds $\times 5$ ) to obtain a single emulsion. This emulsion was poured into the outer water phase and emulsified with ultrasound $(200 \mathrm{~W}$, 5 seconds $\times 2$ ) to obtain the double emulsion. With constant stirring, the double emulsion was immediately dispersed into $0.3 \%$ PVA. The mixture was stirred until the dichloromethane was removed and then was freeze dried. ${ }^{15}$ The drug loading (DL) and encapsulated ratio (ER) percentages were determined by HPLC and calculated per the following equation. 
The particle size was measured using a Nicomp particle sizer (380ZLS; PSS-Nicomp, Port Richey, FL, USA).

Drug loading (\%)

= $\mathrm{mg}$ of encapsulated VLPVPR/100 mg nanoparticles. (1)

Encapsulated ratio (\%)

$=($ actual VLPVPR loading/theoretical VLPVPR loading) $\times 100$.

Optimization of the double emulsion method

The method was optimized in the L(9)34 orthogonal experiment (Table 1). VLPVPR was dissolved in the inner water phase. mPEG-PLGA-PLL (100 mg) was dissolved in $1 \mathrm{~mL}$ dichloromethane. The single emulsion was prepared by ultrasound $(200 \mathrm{~W}, 5$ seconds $\times 5)$. The outer water phase contained 1\% PVA. The DL, ER, and particle size were determined as detailed above.

\section{Preparation of enteric-coated nanoparticles}

The nanoparticles were prepared via the optimized double emulsion method. Eudragit S100 was dissolved in dehydrated alcohol at $1 \mathrm{mg} / \mathrm{mL}$ and then was added dropwise to the mPEG-PLGA-PLL nanoparticle solution with constant stirring. The ratio of mPEG-PLGA-PLL to Eudragit S100 was 100:3.5, 100:7.0, or 100:10.5, respectively. The alcohol was removed by the decompression-volatilization method. The solution was finally freeze dried, and the DL was determined as previously described. ${ }^{16}$

\section{In vitro release of nanoparticles}

The enteric-coated nanoparticles were dispersed in 20 $\mathrm{mL}$ water. Four milliliters of the nanoparticle solution was sealed in dialysis tubing ( $\mathrm{MW}$ cut off $=7,000$ ). The tube was dipped in $46 \mathrm{~mL}$ of $0.1 \mathrm{~mol} / \mathrm{L} \mathrm{HCl}$ or $0.05 \mathrm{M}$ phosphate buffered saline ( $\mathrm{pH}=4.5$ or 7.4$)$, and the release was determined at $37^{\circ} \mathrm{C}$. Samples $(200 \mu \mathrm{L})$ were removed to detect the amount of VLPVPR released from the enteric-coated nanoparticles, and the same volume of fresh

Table I Orthogonal design factors and levels for the double emulsion method

\begin{tabular}{llll}
\hline Factors & \multicolumn{2}{l}{ Level } \\
\cline { 2 - 4 } & $\mathbf{I}$ & $\mathbf{2}$ & $\mathbf{3}$ \\
\hline Inner water phase volume $(\mathrm{mL})(\mathrm{A})$ & 0.1 & 0.2 & 0.4 \\
VLPVPR $(\mathrm{mg})(\mathrm{B})$ & 5 & 7.5 & 10 \\
Outer water phase volume $(\mathrm{mL})(\mathrm{C})$ & $\mathrm{I}$ & 2 & 3 \\
Ultrasound for double emulsion (D) & $5 \mathrm{~s} \times \mathrm{I}$ & $5 \mathrm{~s} \times 2$ & $5 \mathrm{~s} \times 3$ \\
\hline
\end{tabular}

Note: $(A),(B),(C)$, and $(D)$ are used to represent different factors. Abbreviations: s, seconds; VLPVPR, Val-Leu-Pro-Val-Pro-Arg. medium was added. The concentration of VLPVPR was determined by HPLC.

\section{In vivo bioactivity of nanoparticles}

The SBP of the SHR was measured to confirm the in vivo bioactivity of the nanoparticles. Rats that had been given an oral dose of the peptide ( $400 \mu \mathrm{g}$ VLPVPR $/ \mathrm{kg}$ ) or the nanoparticles $\left(3.25,6.5\right.$, and $13 \mathrm{mg} / \mathrm{kg}$, respectively) were kept at $45^{\circ} \mathrm{C}$ for 3 minutes, and the SBP was measured using a tail cuff with a programmed noninvasive blood pressure controller (model ML125; AD Instruments Pty Ltd, Dunedin, New Zealand). A $0.9 \%(\mathrm{~W} / \mathrm{W}) \mathrm{NaCl}$ solution served as the negative control, and the antihypertensive effect of the nanoparticles dissolved in this saline solution was measured. At $0,1,2,4,6,8,10,12$, $16,20,24,30,36$, and 48 hours after the oral administration of the nanoparticles, the SBP of the SHR was measured. At each time point, SBP was measured five times to get the average value. Data are presented as the mean \pm standard deviation and were analyzed statistically using one-way analysis of variance test (StatView Software; Abacus Concepts, Inc, Piscataway, NJ, USA) with a significance level of $P<0.05$, followed by Scheffé's post hoc test.

\section{Results}

\section{Characterization of VLPVPR}

The peak corresponding to VLPVPR was well separated from the other components. The signal to noise ratio $(\mathrm{S} / \mathrm{N})$ equaled 9.7 for $2 \mu \mathrm{g} / \mathrm{mL}$ VLPVPR. The correlation between peak area and VLPVPR concentration was greater than 0.9995 in the concentration range of $2-200 \mu \mathrm{g} / \mathrm{mL}$. The precision, reproducibility, recovery, and stability were all acceptable for a quantitative method.

\section{Optimization of the double emulsion method}

The experimental data obtained from the orthogonal design are shown in Table 2. K1-K3 were the average DL and ER of nanoparticles under the various investigated conditions, and the maximum value was the optimum value. In addition, according to the largest donating rule, the factor with the largest range value $\left(\mathrm{K}_{\max }-\mathrm{K}_{\text {min }}\right)$ had the greatest effect on the preparation of nanoparticles.

In this experiment, the particles were all smaller than $100 \mathrm{~nm}$. Because the particle size was not critical for the optimization, it was not considered. The DL and ER results were analyzed according to the orthogonal experiment (Table 2). The hierarchy of the factors was $\mathrm{D}>\mathrm{A}>\mathrm{B}>\mathrm{C}$. Both D (ultrasound for double emulsion) and A (inner water 
Table 2 Results of the orthogonal experiment

\begin{tabular}{|c|c|c|c|c|c|c|}
\hline & $\begin{array}{l}\text { (A) Inner water } \\
\text { phase volume }(\mathrm{mL})\end{array}$ & $\begin{array}{l}\text { (B) VLPVPR } \\
\text { (mg) }\end{array}$ & $\begin{array}{l}\text { (C) Outer water } \\
\text { phase volume }(\mathrm{mL})\end{array}$ & $\begin{array}{l}\text { (D) Ultrasound of } \\
\text { double emulsion }\end{array}$ & DL (\%) & ER (\%) \\
\hline I\# & 0.1 & 5 & 1 & $5 \mathrm{~s} \times 1$ & 2.96 & 60.97 \\
\hline $2 \#$ & 0.1 & 7.5 & 2 & $5 s \times 2$ & 3.67 & 50.86 \\
\hline $3 \#$ & 0.1 & 10 & 3 & $5 s \times 3$ & 2.37 & 24.25 \\
\hline $4 \#$ & 0.2 & 5 & 3 & $5 s \times 2$ & 2.82 & 57.99 \\
\hline $5 \#$ & 0.2 & 7.5 & I & $5 s \times 3$ & 6.31 & 89.8 \\
\hline $6 \#$ & 0.2 & 10 & 2 & $5 s \times 1$ & 5.06 & 53.34 \\
\hline 7\# & 0.4 & 5 & 2 & $5 s \times 3$ & 2.28 & 46.65 \\
\hline $8 \#$ & 0.4 & 7.5 & 3 & $5 \mathrm{~s} \times 1$ & 2.37 & 32.38 \\
\hline 9\# & 0.4 & 10 & I & $5 s \times 2$ & 5.07 & 53.44 \\
\hline \multicolumn{7}{|l|}{ DL } \\
\hline $\mathrm{KI}$ & 9.00 & 8.06 & 10.39 & 14.34 & \multirow{5}{*}{\multicolumn{2}{|c|}{$\begin{array}{l}\text { Calibration parameter } \\
=120.38\end{array}$}} \\
\hline $\mathrm{K} 2$ & 14.19 & 12.36 & I I.57 & II.02 & & \\
\hline $\mathrm{K} 3$ & 9.72 & 12.50 & 10.96 & 7.56 & & \\
\hline$S$ & 5.27 & 4.26 & 0.23 & 7.67 & & \\
\hline $\mathrm{F}$ & $23.02 *$ & 18.58 & 1.00 & $33.5 I^{*}$ & & \\
\hline \multicolumn{7}{|l|}{ ER } \\
\hline $\mathrm{KI}$ & 136.08 & $165.6 \mid$ & 146.69 & 204.21 & \multirow{5}{*}{\multicolumn{2}{|c|}{$\begin{array}{l}\text { Calibration parameter } \\
=24,5 \text { I I. } 03\end{array}$}} \\
\hline $\mathrm{K} 2$ & 201.13 & 173.04 & 162.29 & 150.85 & & \\
\hline $\mathrm{K} 3$ & 132.47 & 131.03 & 160.70 & 114.62 & & \\
\hline$S$ & 995.41 & 335.09 & 49.13 & I,354.03 & & \\
\hline $\mathrm{F}$ & $20.26 *$ & 6.82 & 1.00 & $27.56 *$ & & \\
\hline
\end{tabular}

Note: *Significant $(P<0.05)$ by Student's $t$-test.

Abbreviations: DL, drug loading; ER, encapsulated ratio; F, statistical analysis results for orthogonal experiment; $\mathrm{K}$, the average DL and ER of nanoparticles under the various investigated conditions; S, standard deviation; s, seconds; VLPVPR, Val-Leu-Pro-Val-Pro-Arg.

phase volume) significantly affected DL and ER. The best combination for achieving the highest DL was $\mathrm{A}_{2} \mathrm{~B}_{3} \mathrm{C}_{2} \mathrm{D}_{1}$, whereas $\mathrm{A}_{2} \mathrm{~B}_{2} \mathrm{C}_{2} \mathrm{D}_{1}$ realized the highest ER.

\section{Nanoparticle preparation methods}

The nanoparticles prepared by the optimized double emulsion method had an average diameter of $75.2 \mathrm{~nm}$ and a narrow dispersion with PI $=0.171$ (Figures 1 and 2), $E R=86.94 \%$, and $\mathrm{DL}=6.12 \%$ (Table 3 ).

\section{In vitro release of nanoparticles}

The release of free VLPVPR at 2 hours was approximately $80 \%$ (Figure 3), indicating that the dialysis tube did not hinder drug release. VLPVPR release from the enteric-coated nanoparticles was $\mathrm{pH}$-sensitive (Figures 4-6). At $\mathrm{pH}$ 1.0, the nanoparticles sustained the release compared with free VLPVPR. Among the three enteric-coated nanoparticles, the third one (mPEG-PLGA-PLL:Eudragit S100 100:10.5) possessed the best $\mathrm{pH}$-sensitive profile; that is, the entericcoated nanoparticles released drug mostly in the small intestine, where $\mathrm{pH}$ value is about 7.4, to protect VLPVPR from degradation by proteolytic enzymes. At $\mathrm{pH} 7.4$, drug release was slower than that of the free drug, whereas the drug release from the other two nanoparticles was similar at $\mathrm{pH} 4.5$ and 7.4.

\section{In vivo bioactivity of the nanoparticles}

At $0,1,2,4,6,8,12,16,20,24,30,36$, and 48 hours after oral administration of the recombinant AHP, the SBP of SHR was measured (Figure 5). The SBP of spontaneously hypertensive rats was dramatically decreased by recombinant AHP at an oral

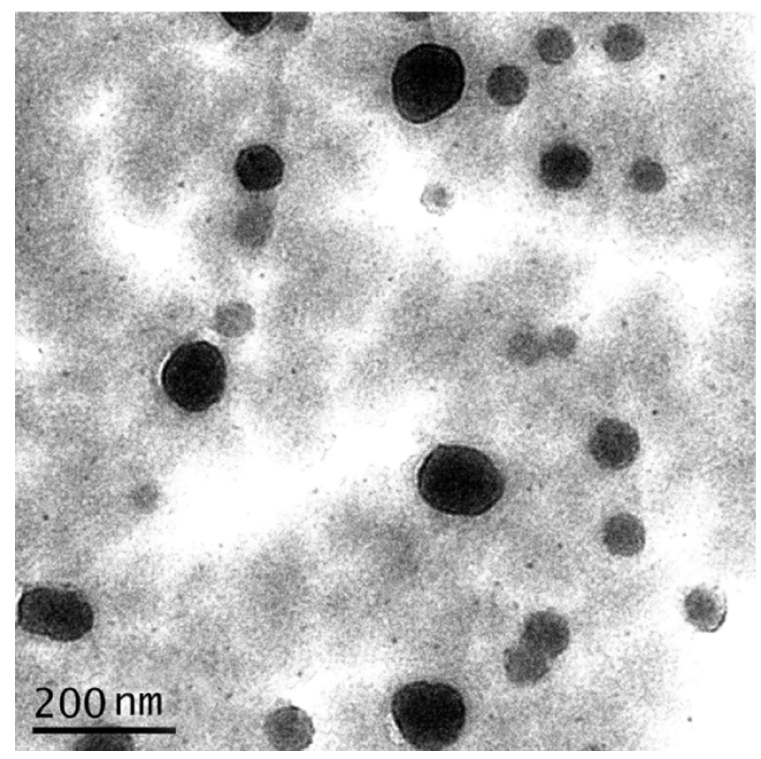

Figure I Typical SEM images of mPEG-PLGA-PLL nanoparticles coated with Eudragit SI00; bar, $200 \mathrm{~nm}$.

Abbreviations: mPEG-PLGA-PLL, (Methoxy-polyethylene glycol)-b-poly(D,Llactide-co-glycolide)-b-poly(L-lysine); SEM, scanning electron microscopy. 


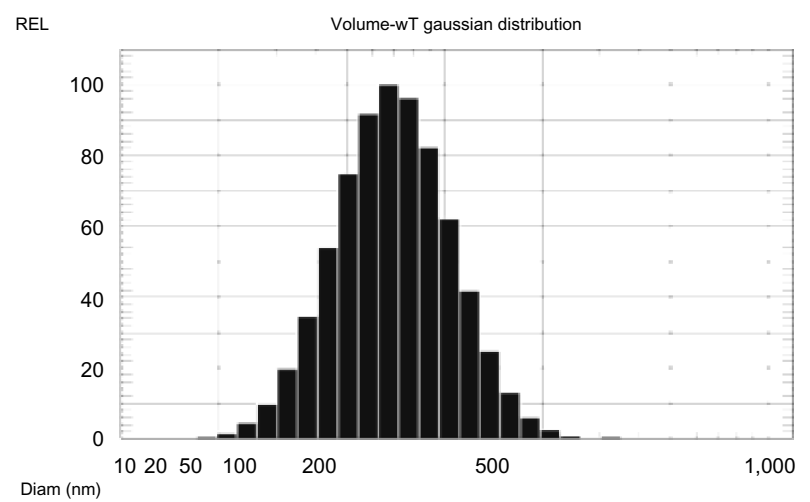

Figure 2 Particle size of nanoparticles prepared using the double emulsion method.

dose of $0.4 \mathrm{mg} \mathrm{AHP} / \mathrm{kg}$ body weight. The antihypertensive effect was obtained 2-6 hours after oral administration, with a peak during the second hour $(-43 \pm 7.9 \mathrm{mmHg})$.

Different doses of AHP-loaded nanoparticles (3.25, 6.5, and $13 \mathrm{mg} / \mathrm{kg}$ ) were given orally to SHR, and the effects were compared with the control group. As shown in Figure 5, the SBP did not significantly decrease at the $3.25 \mathrm{mg} / \mathrm{kg}$ dose. However, $6.5 \mathrm{mg} / \mathrm{kg}$ and $13 \mathrm{mg} / \mathrm{kg}$ significantly decreased SBP in a dose-dependent manner compared with the negative control group. The effect peaked at 6 hours and lasted for approximately 30 hours. The SBP did not change in the negative control rats in the 48 hours after drug administration.

\section{Discussion}

VLPVPR is a water-soluble peptide. It is stable below $0^{\circ} \mathrm{C}$ for 30 days, at $4^{\circ} \mathrm{C}$ for 7 days, at $37^{\circ} \mathrm{C}$ for 48 hours, and at $60^{\circ} \mathrm{C}$ for 24 hours. It is stable between $\mathrm{pH} 5.0$ and $\mathrm{pH} 9.2$. It degraded after exposure to $200 \mathrm{~W}$ ultrasound for $15 \mathrm{~min}$ utes, $400 \mathrm{~W}$ for 7 minutes, or $600 \mathrm{~W}$ for 5 minutes (data not shown). Therefore, the nanoparticles should be prepared quickly, and high temperature, extreme $\mathrm{pH}$, and intense ultrasound should be avoided. Methods to prepare peptide nanoparticles include double emulsion and ionic gelation.

The emulsion-solvent evaporation method is popular for preparing PLGA nanoparticles because it yields small, uniform, round particles with a smooth surface.

Table 3 Characterization of nanoparticles prepared by the optimized double emulsion method

\begin{tabular}{llll}
\hline Groups & ER (\%) & DL (\%) & $\begin{array}{l}\text { Average } \\
\text { diameter }(\mathbf{n m})\end{array}$ \\
\hline $\mathrm{I}$ & 88.22 & 6.21 & $76.3 \pm 19.8$ \\
2 & 85.30 & 6.01 & $79.0 \pm 25.6$ \\
3 & 87.29 & 6.14 & $70.2 \pm 18.9$ \\
Average & 86.94 & 6.12 & $75.2 \pm 21.4$ \\
\hline
\end{tabular}

Abbreviations: DL, drug loading; ER, encapsulated ratio.

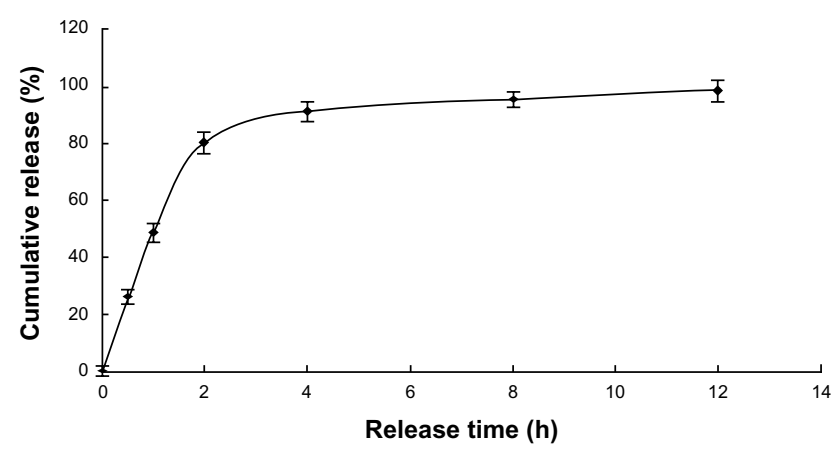

Figure 3 Cumulative release of free VLPVPR in PBS $(\mathrm{pH}=7.4)$. Abbreviations: h, hours; PBS, phosphate buffered saline; VLPVPR, Val-Leu-ProVal-Pro-Arg.

Commonly, hydrophobic PLGA is dissolved in an organic solvent. If the drug is also hydrophobic, it is dissolved with the PLGA. This organic phase is emulsified with an aqueous phase to make an $\mathrm{O} / \mathrm{W}(\mathrm{O}$, oil, W, water, O/W, oil-in-water emulsion) single emulsion. If the drug is hydrosoluble, it is dissolved in an aqueous phase $\mathrm{W}_{1}$, which is emulsified in the PLGA organic solution to make $\mathrm{a}_{1} / \mathrm{O}$ emulsion. This emulsion is emulsified in a second aqueous phase $\mathrm{W}_{2}$ to form a $\mathrm{W}_{1} / \mathrm{O} / \mathrm{W}_{2}$ double emulsion. ${ }^{17}$ VLPVPR is a water-soluble drug, therefore, the double emulsion method is preferable. PLGA is a biocompatible polymer, but because it is hydrophilic, it does not allow for substantial DL of water-soluble drugs. We chose mPEG-PLGA-PLL as the polymer to form the double emulsion because the hydrophilic block in this polymer was compatible with the peptide and the hydrophobic block could form the emulsion. The ion gelation method is also commonly used to prepare peptide nanoparticles. ${ }^{15}$

The nanoparticles were designed to be enteric targeting. Therefore, the encapsulating material should dissolve in neutral or basic media and release the drug, but remain intact in acidic media to protect the drug from gastric juices. mPEG-PLGA-PLL does not possess this enteric-dissolving characteristic. The nanoparticles should be made of an enteric-dissolving material or be coated with an entericcoating material. Eudragit S100 is a popular coating material that dissolves at $\mathrm{pH}>7.0$. It is an anionic polymer synthesized from methacrylic acid and methacrylic acid methyl ester and exhibits pH-dependent solubility. Furthermore, it is liposoluble with poor peptide compatibility and does not dissolve in low polarity and volatile organic solvents such as dichloromethane; therefore, it cannot form the double emulsion to entrap VLPVPR, but can be used to coat the outside of the nanoparticles.

The characteristics of the single emulsion $\left(\mathrm{W}_{1} / \mathrm{O}\right)$ are important for the stability of the double emulsion $\left(\mathrm{W}_{1} / \mathrm{O} / \mathrm{W}_{2}\right)$. 

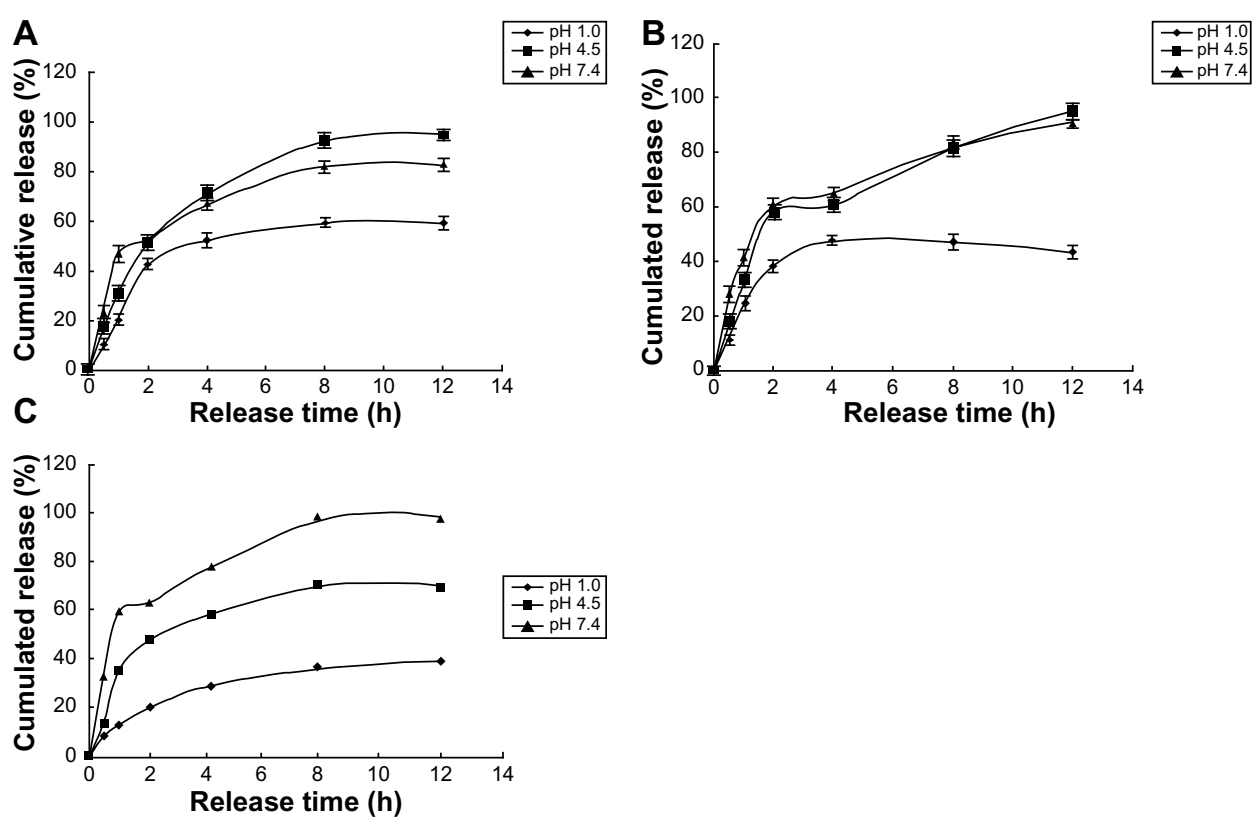

Figure 4 Cumulative release of three enteric-coated nanoparticles in different $\mathrm{pH}$ media.

Notes: (A) Cumulative release of enteric-coated nanoparticles (mPEG-PLGA-PLL:Eudragit SI00 I00:3.5) in pH I.0, 4.5, and 7.4 media. (B) Cumulative release of entericcoated nanoparticles (mPEG-PLGA-PLL:Eudragit SI00 100:7) in pH I.0, 4.5, and 7.4 media. (C) Cumulative release of enteric-coated nanoparticles (mPEG-PLGA-PLL:Eudragit SI00 100:10.5) in $\mathrm{PH} 1.0,4.5$, and 7.4 media.

Abbreviations: h, hours; mPEG-PLGA-PLL, (Methoxy-polyethylene glycol)-b-poly(D,L-lactide-co-glycolide)-b-poly(L-lysine).

The drug entrapped in the single emulsion can escape via several routes: molecular diffusion, micelle transport, and disruption of the oil drops. ${ }^{18-20}$ Therefore, a stable single emulsion with a small drop size is necessary to obtain a stable double emulsion with a high DL. We decided to prepare the single emulsion by ultrasound to obtain the smallest possible drop size. We also studied factors that affected the DL and ER. As shown in Tables 1 and 2, the inner water phase volume and the ultrasound parameters for the double emulsion had a significant influence on these particular variables.
A small inner water phase volume will yield a small drop size in a single emulsion. In the optimization experiment (Tables 1 and 2), the DL and ER increased when the inner water phase volume decreased from $0.4 \mathrm{~mL}$ to $0.2 \mathrm{~mL}$, but dropped when it decreased further. Perhaps when the inner water phase volume fell too low, the drug pressure increased and disrupted the oil drop. The level in $\mathrm{A}_{2}$ was the best. The DL increased as the drug dose increased, with the result $\mathrm{B}_{1}<\mathrm{B}_{2} \approx \mathrm{B}_{3}$, but for the ER, the result was $\mathrm{B}_{1} \approx \mathrm{B}_{2}>\mathrm{B}_{3}$. This factor was not as important; therefore, we chose $\mathrm{B}_{2}$.

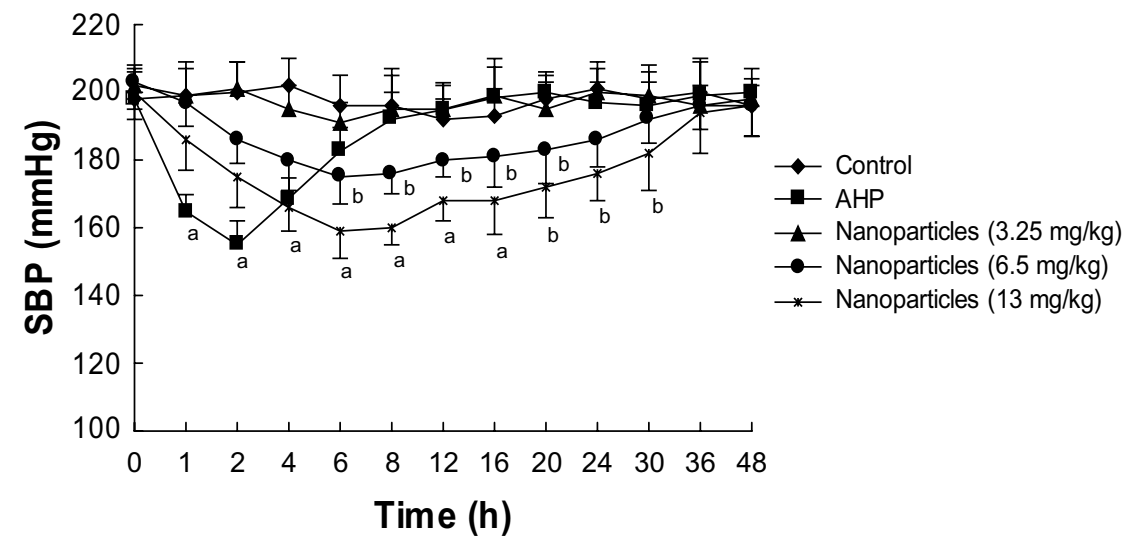

Figure 5 Effects of a single oral dose of mPEG-PLGA-PLL nanoparticles on SBP in SHR.

Notes: $n=8, \bar{X} \pm$ s. Letters indicate the level of significant difference from control: ${ }^{a} P<0.01 ;{ }^{b} P<0.05$.

Abbreviations: AHP, antihypertensive peptides; mPEG-PLGA-PLL, (Methoxy-polyethylene glycol)-b-poly(D,L-lactide-co-glycolide)-b-poly(L-lysine); s, seconds; SBP, systolic blood pressure; SHR, spontaneously hypertensive rats. 
In this study, the DL did not change as the outer water phase volume increased. The ER exhibited a trend of increasing first and then stabilizing; this may be because the ratio of the volume of the outer water phase to that of the single emulsion affected the drop size of the double emulsion. Big double emulsion drops can entrap more inner water drops, but a greater outer continuous phase is more important for stability. Furthermore, if the outer water phase is too small, the resulting double emulsion will be too viscous, which will get more broadly dispersed. The level $\mathrm{C}_{2}$ was the best. The ultrasound parameters for the double emulsion significantly impacted the DL and ER. Ultrasound that was too strong resulted in drop disruption and drug leakage. Therefore, we chose $\mathrm{D}_{1}$.

According to the DL and ER results, we chose the optimized $\mathrm{A}_{2} \mathrm{~B}_{2} \mathrm{C}_{2} \mathrm{D}_{1}$ method, which proved to be reproducible. Because the nanoparticles had been freeze-dried before the DL and ER were measured, the results may have been artificially high due to the instability of VLPVPR.

Compared with the drug release of free VLPVPR (Figure 3), the enteric-coated nanoparticles postpone drug release at different $\mathrm{pH}$ values $(\mathrm{pH} 1.0,4.5$, and 7.5). Figures 4A and B showed the enteric-coated nanoparticles (mPEG-PLGA-PLL:Eudragit S100 100:3.5, mPEG-PLGAPLL:Eudragit S100 100:7) release drug more slowly at pH 1.0 in 12 hours than that of free VLPVPR, but in 4 hours the drug release still increase to $40 \%$. For these two kinds of entericcoated nanoparticles, the release curves are similar at $\mathrm{pH} 4.5$ and 7.4, indicating that VLPVPR can also release in the duodenum ( $\mathrm{pH} 4.5$ ) where it may be degraded by gastric juices. Based on the release results, the most suitable $\mathrm{pH}$ sensitivity profile occurred at the ratio of mPEG-PLGA-PLL to enteric coat of 100:10.5 (Figure 4C). The human stomach (pH 1.0) emptying time is $1-3$ hours. Orally administered drugs pass quickly through the duodenum, remain for 4-6 hours in the small intestine (pH 6.8), and spend approximately 12 hours in the colon ( $\mathrm{pH}$ 7.4). According to the release results for the enteric-coated nanoparticles, the release ratio in the first several hours was low in the $\mathrm{pH}$ corresponding to the stomach or small intestine. Because VLPVPR is unstable, our release experiment was only performed for 12 hours, but in vivo it would be absorbed at the same time it is released.

Until now, we did not have sufficient pharmacokinetics data on VLPVPR because it is unstable and easily degraded. Therefore, the in vivo experiments were carried out to illustrate the slow-release effect of the enteric-coated nanoparticles compared with that of free VLPVPR. The results showed that nanoparticles significantly decreased SBP in a dose-dependent manner and lasted for approximately 30 hours, while the antihypertensive effect of free VLPVPR lasts for only 6 hours (Figure 5). A grant supported by the government on how to develop and validate pretreatment methods and ultra performance liquid chromatographymass spectrometry. methods for the determination of the antihypertensive peptide is ongoing in our lab, which will shed light on drug metabolism and pharmacokinetics.

\section{Conclusion}

This study determined the best preparation of VLPVPR enteric-coated nanoparticles. mPEG-PLGA-PLL was utilized as the entrapping material. The nanoparticles were prepared using the double emulsion method, coated with Eudragit S100, and freeze dried.

The optimized double emulsion method was obtained from orthogonal experiments. The best method was the following: VLPVPR $(10 \mathrm{mg})$ was dissolved in $0.2 \mathrm{~mL}$ water to form the inner water phase. mPEG-PLGA-PLL $(100 \mathrm{mg})$ was dissolved in $1 \mathrm{~mL}$ dichloromethane for the oil phase. The single emulsion was prepared by ultrasound (5 seconds $\times 5$ times). Two milliliters of a $1 \%$ PVA solution was utilized as the outer water phase. The double emulsion was prepared by a single 5 -second ultrasound burst. The emulsion was quickly dispersed into $50 \mathrm{~mL}$ of a $0.3 \%$ PVA solution and stirred until the dichloromethane was removed. The Eudragit S100 was dissolved in ethanol and added dropwise into the nanoparticle solution at a ratio of mPEG-PLGA-PLL:Eudragit S100 of 100:10.5. Ethanol was removed by decompression, and the solution was freeze-dried to produce the enteric-coated nanoparticles.

The release experiment confirmed the $\mathrm{pH}$ sensitivity of the nanoparticles. VLPVPR was almost completely released at $\mathrm{pH} 7.4$ after 8 hours, but much less was released at $\mathrm{pH} 4.5$ or $\mathrm{pH} 1.0$ in the same amount of time. The in vivo experiments carried out in SHR shows the slow-release antihypertensive effect of the nanoparticles either. A better method to detect VLPVPR concentration in plasma is needed to help us interpret and predict metabolism and pharmacokinetics of the VLPVPR-loaded nanoparticles in rats in further study. The data demonstrated that nanoparticles significantly decreased SBP, and the antihypertensive effect lasted for approximately 30 hours, which confirmed the slow-release of the entericcoated nanoparticles in vivo.

\section{Acknowledgments}

This study was supported by Science and Technology Planning Project of Guangdong Province (NO:2009B030803016). 
The project was supported by GDHVPS (2011), Science and Technology Planning Project of Guangdong Province (NO:2011B010500006) and Shenzhen Science and Technology Planning Project (NO:ZDSY20120619093923525).

\section{Disclosure}

The authors report no conflicts of interest in this work.

\section{References}

1. Pereira M, Lunet N, Azevedo A, Barros H. Differences in prevalence, awareness, treatment and control of hypertension between developing and developed countries. J Hypertens. 2009;27(5):963-975.

2. Chobanian AV, Bakris GL, Black HR, et al. Seventh report of the Joint National Committee on Prevention, Detection, Evaluation, and Treatment of High Blood Pressure. Hypertension. 2003;42:1206-1252.

3. Karaki H, Doi K, Sugano S, et al. Antihypertensive effect of tryptic hydrolysate of milk casein in spontaneously hypertensive rats. Comp Biochem Physiol C. 1990;96(2):367-371.

4. Yoshikawa M, Fujita H, Matoba N, et al. Bioactive peptides derived from food proteins preventing lifestyle-related diseases. Biofactors. 2000;12(1-4):143-146.

5. Iroyukifujita H, Eiichiyokoyama K, Yoshikawa M. Classification and antihypertensive activity of angiotensin i-converting enzyme inhibitory peptides derived from food proteins. J Food Science. 2000;65:564-569.

6. Liu D, Sun H, Zhang L, Li S, Qin Z. High-level expression of milk-derived antihypertensive peptide in Escherichia coli and its bioactivity. J Agric Food Chem. 2007;55(13):5109-5112.

7. Sun H, Liu D, Li S, Qin Z. Transepithelial transport characteristics of the antihypertensive peptide, Lys-Val-Leu-Pro-Val-Pro, in human intestinal Caco-2 cell monolayers. Biosci Biotechnol Biochem. 2009;73(2): 293-298.

8. Panyam J, Labhasetwar V. Biodegradable nanoparticles for drug and gene delivery to cells and tissue. Adv Drug Deliv Rev. 2003;55(3): $329-347$.
9. Yuan W, Liu Z. Controlled-release and preserved bioactivity of proteins from (self-assembled) core-shell double-walled microspheres. Int $J$ Nanomedicine. 2012;7:257-270.

10. Yin P, Wang Y, Qiu Y, et al. Bufalin-loaded mPEG-PLGA-PLL-cRGD nanoparticles: preparation, cellular uptake, tissue distribution, and anticancer activity. Int J Nanomedicine. 2012;7:3961-3969.

11. Liu P, Wang H, Wang Q, et al. cRGD conjugated mPEG-PLGA-PLL nanoparticles for SGC-7901 gastric cancer cells-targeted delivery of fluorouracil. J Nanosci Nanotechnol. 2012;12(6):4467-4471.

12. Jain D, Panda AK, Majumdar DK. Eudragit S100 entrapped insulin microspheres for oral delivery. AAPS PharmSciTech. 2005;6(1): E100-E107.

13. Yin Y, Chen D, Qiao M, Wei X, Hu H. Lectin-conjugated PLGA nanoparticles loaded with thymopentin: ex vivo bioadhesion and in vivo biodistribution. J Control Release. 2007;123(1):27-38.

14. He W, Jiang X, Zhang ZR. Preparation and evaluation of poly-butylcyanoacrylate nanoparticles for oral delivery of thymopentin. J Pharm Sci. 2008;97(6):2250-2259.

15. Xu D, Wu F, Chen Y, Wei L, Yuan W. pH-sensitive degradable nanoparticles for highly efficient intracellular delivery of exogenous protein. Int J Nanomedicine. 2013;8:3405-3414.

16. Zheng AP, Wang KS, Hao R. Study on preparation release in vitro and biological activity of thymopentin-loaded $\mathrm{pH}$-sensitive chitosan nanoparticles for oral administration. Chin Pharm J. 2007;42:679-685.

17. Tewes F, Munnier E, Antoon B, et al. Comparative study of doxorubicinloaded poly(lactide-co-glycolide) nanoparticles prepared by single and double emulsion methods. Eur J Pharm Biopharm. 2007;66(3): 488-492.

18. Omotosho JA, Whateley TL, Florence AT. Methotrexate transport from the internal phase of multiple $\mathrm{w} / \mathrm{o} / \mathrm{w}$ emulsions. J Microencapsul. 1989;6(2):183-192.

19. Ficheux M-F, Bonakdar L, Leal-Calderon F, Bibette J. Some stability criteria for double emulsions. Langmuir. 1998;14(10):2702-2706.

20. Garti N, Magdassi S, Whitehill D. Transfer phenomena across the oil phase in water-in oil-in water multiple emulsion evaluated by Coulter Counter I. Effect of emulsifier 1 on water permeability. $J$ Colloid Interface Sci. 1985;104(2):587-591.
International Journal of Nanomedicine

\section{Publish your work in this journal}

The International Journal of Nanomedicine is an international, peerreviewed journal focusing on the application of nanotechnology in diagnostics, therapeutics, and drug delivery systems throughout the biomedical field. This journal is indexed on PubMed Central, MedLine, CAS, SciSearch $\AA$, Current Contents $₫ /$ Clinical Medicine,

\section{Dovepress}

Journal Citation Reports/Science Edition, EMBase, Scopus and the Elsevier Bibliographic databases. The manuscript management system is completely online and includes a very quick and fair peer-review system, which is all easy to use. Visit http://www.dovepress.com/ testimonials.php to read real quotes from published authors. 